\title{
ADEQUAÇÃO DO PROCOM(N2) DO LAMINADOR DE TIRAS A FRIO \#2 DA CSN PARA COMUNICAÇÃO COM O NOVO SISTEMA DE CONTROLE DE PROCESSO (N1)*
}

\author{
Flaviano Galdino 1 \\ Luiz Carlos de Paula Junior ${ }^{2}$ \\ Jonnatha da Silva Barahona ${ }^{3}$ \\ José Luiz Costa Pereira ${ }^{4}$
}

\section{Resumo}

Com a implantação do projeto de digitalização do Nível 1 no laminador de tiras a frio da CSN - Companhia Siderúrgica Nacional, a CSN modernizou o obsoleto controle de processo. Com essa modernização, houve a necessidade de adequação no Procom para manter a comunicação entre eles. Devido a essa necessidade, foi elaborado um plano estratégico para a atualização tecnológica deste Procom. 0 projeto foi divido em fases e o que vamos apresentar é resultado da primeira fase, onde a CSN desenvolveu com recurso interno.

Palavras-chave: Adaptação; Controle de processo; Procom; Desenvolvimento; OPC

\section{ADAPTATION OF PROCOM (LEVEL 2) OF THE TANDEM COLD MILL \#2 WITH NEW LEVEL 1 COMMUNICATION WITH THE NEW PROCESS CONTROL SYSTEM (LEVEL 1)}

\section{Abstract}

With the implementation of the digitization project of Level 1 in the Tandem Cold Mill of CSN - Companhia Siderúrgica Nacional, CSN has modernized the outdated process control. With this modernization, there was the need to adapt the Process computer to maintain communication between them. Due to this need, a strategic plan for technological upgrading this Procom was prepared. The project was divided into phases and we'll present results from the first phase, where CSN developed with internal resources.

Keywords: Adaptation; Process control; Process computer; Development; OPC.

Bacharel em Ciências da Computação, Analista de TI, CSN, Volta Redonda, RJ - Brasil.

Tecnólogo em Processamento de Dados, Analista de TI, CSN, Volta Redonda, RJ - Brasil. Engenheiro de Computação, Analista de TI, CSN, Volta Redonda, RJ - Brasil.

Engenheiro Eletricista, Volta Redonda, RJ - Brasil

* Contribuição técnica ao $18^{\circ}$ Seminário de Automação e TI Industrial, 23 a 26 de setembro de 2014, São Paulo, SP, Brasil. 


\section{INTRODUÇÃO}

Parada na linha de produção é o que toda indústria competitiva quer evitar. Qualquer melhoria que reduza tempo, seja na hora de fazer um "preset", enviar dados para um sistema de uma camada acima (MES), será bem recebido pelo operador líder da linha, engenheiro de processo e afins.

Uma linha com equipamento obsoleto, que não tem peças de reposição no mercado e que não há mão de obra especializada para manutenção, está fadada a sofrer paradas e, consequentemente, perda de produção. A necessidade de atender mais clientes leva a empresa a modernizar seus equipamentos.

Com a CSN não foi diferente. A linha de Laminação a Frio 2, o LTF 2, estavam numa situação parecida. A LTF 2 tinha como controle do processo o HIDIC-08 que apresentava algumas das seguintes funções:

- Controle automático de posicionamento de bobina (APC)

- Controle automático da espessura da bobina (AGC)

- Controle automático de troca de cilindros

O HIDIC-08 não possuía:

- Controle de preset automático,

- Entrada manual de presets,

- Controle automático de tracking,

- Armazenamento de dados do processo.

A LTF 2 tinha um Sistema de nível 2, (PROCOM) que se comunicava com o sistema de controle (Nível 1) via serial. Também tinha módulo ADAM que obtinha poucos sinais do laminador, cerca de quinze, para fazer as suas funções.

O sistema de Nível 2 não estava totalmente obsoleto. Foi possível adaptá-lo para sobreviver por mais algum tempo e atender às solicitações dos usuários. Também existe mão de obra para poder mantê-lo na CSN. O que não foi possível atualizar ou modificar era o modelo matemático, pois não se acha mais o compilador que foi utilizado. Somente a reescrita do modelo em outra linguagem de programação é possível.

Antes da digitalização, o Nível 2 calculava os presets e o operador ajustava o equipamento manualmente, conforme era mostrado na IHM do Nível 2.

Todos os equipamentos de controle de Nível 1 (HIDIC-08) foram substituídos durante o projeto de digitalização do controle pela empresa mexicana AMI GE. Como o projeto não contemplava melhorias no sistema de Nível 2 e não havia tempo pra contratar uma empresa pra desenvolver um novo sistema, foi necessário adequar o sistema que já possuíamos. Só tínhamos três meses para esta tarefa.

Montamos um laboratório, reunimos a equipe responsável pela manutenção dos sistemas de Nível 2 da laminação da CSN, fizemos os levantamentos necessários e identificamos as modificações necessárias no sistema.

A começar pela parte de comunicação com o Nível 1. Antes, a comunicação com o HIDIC-08 era via serial RS232, com baixa velocidade. Para o controle do status das cadeiras do laminador era utilizado módulo ADAM. Este módulo era responsável em receber os sinais, vindos do laminador e digitalizá-lo para uso do Nível 2 e a comunicação era também via serial RS232.

A comunicação era lenta, informações eram perdidas e sempre havia perda de sincronismo entre Nível 2 e Nível 1.

* Contribuição técnica ao $18^{\circ}$ Seminário de Automação e TI Industrial, 23 a 26 de setembro de 2014, São Paulo, SP, Brasil. 


\section{MATERIAIS E MÉTODOS}

\subsection{Arquitetura do Sistema de Nível 2}

O Nível 2 da LTF 2 é simples. Possuía processos para tracking das bobinas, leituras dos dados reais vindos do HIDIC-08, log, modelo matemático, recebia os dados primários do material que seria laminado, comunicação com o Stressometter, etc..

O sistema foi desenvolvido na década de 80 pela própria CSN, rodava em VMS. Aos poucos, foi sendo migrado para as novas tecnologias que surgia no decorrer da evolução tecnológica. Começou utilizando somente Fortran 77 e, com o passar do tempo ganhou processos escritos em ANSI C e a IHM em VB6.

Para comunicação interprocesso é usada a Mailslot do Windows. A Mailslot é análoga a uma caixa de correspondência. É como se um Processo $A$ enviasse uma carta para o Processo B, colocando a carta na caixa de correspondência do Processo B. O processo fica verificando sua caixa para ver se tem alguma mensagem.

O nível 2 não tinha um banco de dados relacional. As informações necessárias eram armazenadas em tabelas binárias. Não era possível ter um histórico do que foi produzido nem modificado. Pouca coisa era armazenada.

Na Figura 1 é apresentada a antiga arquitetura de N2.

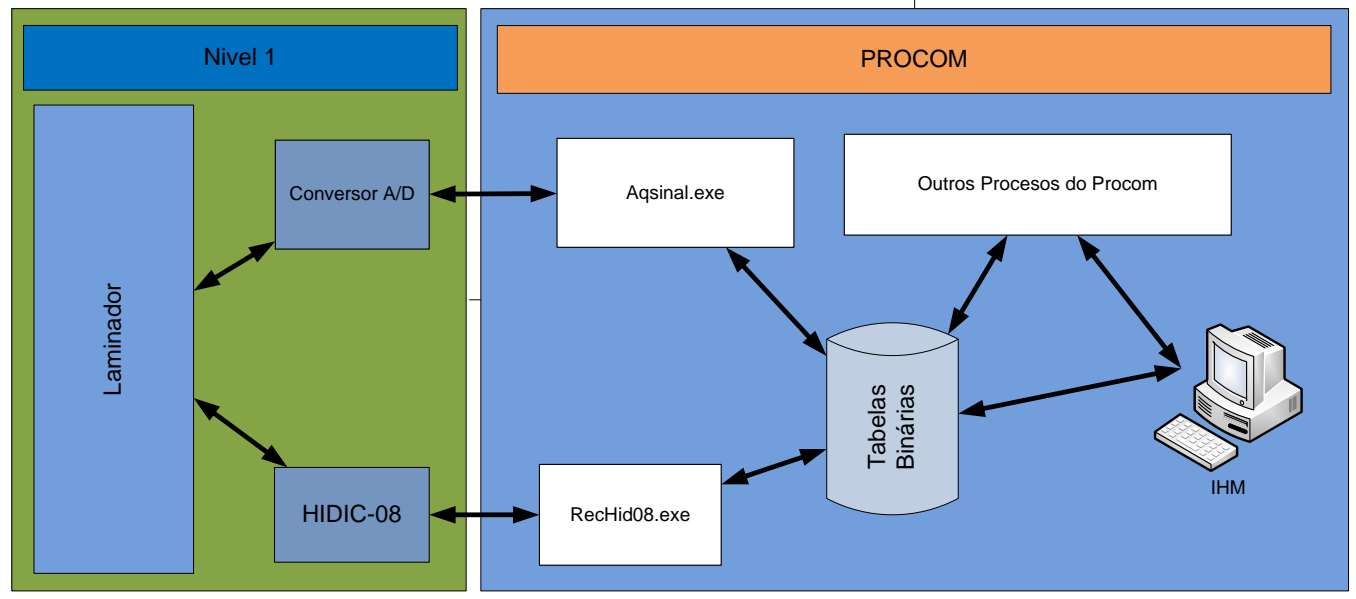

Figura 1 - Arquitetura antes do projeto de digitalização

\subsection{Desenvolvimento}

Com a saída do HIDIC-08, o processo que era responsável por ler as informações dos dados reais para o modelo adaptativo e para geração dos relatórios, deixou de existir. Os outros foram modificados para receber informações de um novo processo escrito em dotNET. Mais dois processos foram criados. Um processo faz a ponte dos processos legados com os processos em dotNET. Um processo faz a comunicação com o novo controle de processo via OPC. O outro gerencia os eventos necessários ao funcionamento do nível 2.

Foi também adicionado um banco de dados SQL Server 2008 Express para fazer histórico e também a troca de dados entre os sistemas legados e os novos. Todos estes novos processos dotNET acessam o banco de dados.

\footnotetext{
* Contribuição técnica ao 18 Seminário de Automação e TI Industrial, 23 a 26 de setembro de 2014,
} São Paulo, SP, Brasil. 
Durante o desenvolvimento foi encontrado um problema de compatibilidade. Os processos escritos em ANSI C utilizavam uma DLL (Dinamic Link library) que encapsulava as funções Mailslot da API do Windows. As mensagens trocadas tinham um formato que não era possível em um curto espaço de tempo, devido à urgência de entrega, escrever uma DLL dotNET, capaz de entender o formato da mensagem. Para resolver, foi criando um processo que era capaz de entender as mensagem da Mailslot dos processos ANSI C e "traduzi-lo" para Mailslot dos processos dotNET, fazendo uma ponte entre os processos dotNET e os processo ANSI C.

Na Figura 2, podemos ver a nova arquitetura do sistema.

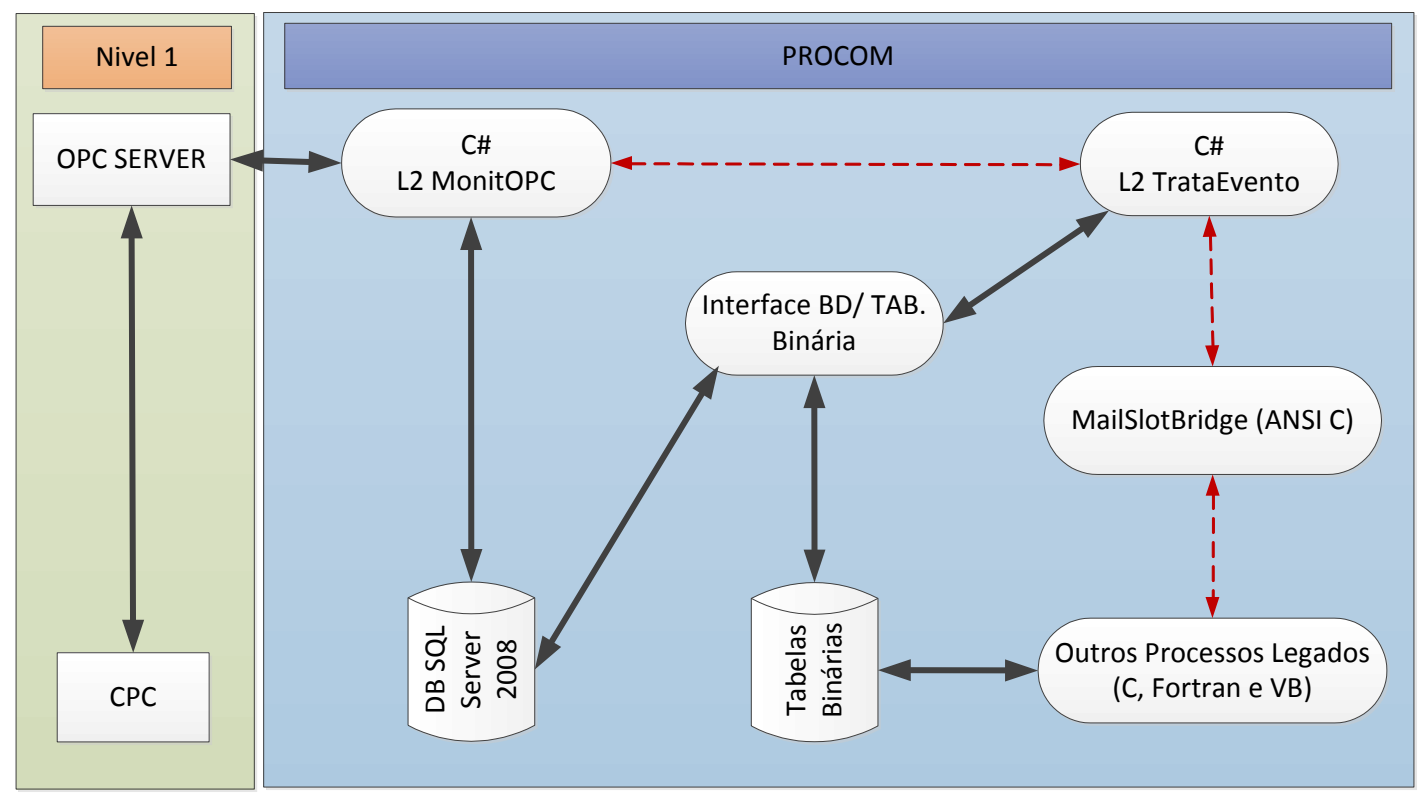

Figura 2. Nova arquitetura do Nível 2.

Para comunicação com o Nível 1 foi utilizado o padrão OPC. Foi um desenvolver do processo utilizando esta tecnologia. A equipe tinha pouco conhecimento sobre OPC. Nada tinha sido desenvolvido utilizando este padrão OPC pela equipe sendo este 0 primeiro trabalho.

\section{RESULTADOS E DISCUSSÃO}

Com a adequação, foi possível melhorar a comunicação com o controle de processo. Temos mais informações do processo, melhor tracking das bobinas ao longo do laminador. O risco de erro é minimizado. O nível 2 envia os presets ao controle. Foi possível, também, uma integração com as tabelas binárias que o modelo matemático faz uso. Ganhou-se uma melhor rastreabilidade das bobinas produzidas, que só era possível buscando em relatórios binários, olhando um a um. Hoje o Nível 2 está funcionando em um computador com Windows 764 bits e para banco de dados o SQL Server 2008 Express. Os processos dotNET foram desenvolvidos utilizando o Framework 4. Todos os processos são em 32 bits.

* Contribuição técnica ao $18^{\circ}$ Seminário de Automação e TI Industrial, 23 a 26 de setembro de 2014, São Paulo, SP, Brasil. 


\section{CONCLUSÃo}

Ainda há muito trabalho e melhorias para serem feitas. No Nível 2, citamos a comunicação com sistema de Controle de Cilindros; melhor comunicação com o sistema M.E.S, removendo o antigo DEC Message $Q$. Reescrita do modelo matemático.

Quando se atualiza uma planta com o que há de mais moderno, é possível se obter diversos ganhos de tempo, estabilidade, e manutenção também.

\section{Agradecimentos}

Ao Gilberto Ribeiro pela ajuda durante o projeto. 